\title{
Atividades de extensão universitária no contexto do geoprocessamento e de recursos hídricos em uma escola pública de ensino médio no município de Bagé, Rio Grande do Sul
}

University extension activities in the context of geoprocessing and water resources in a public high school in Bagé, State of Rio Grande do Sul, Brazil

Alexandro Gularte Schäfer ${ }^{1}$

\section{RESUMO}

Este texto apresenta ações de extensão universitária desenvolvidas na Escola Estadual de Ensino Médio Dr. Karlos Kluwe, no município de Bagé-RS, no âmbito do projeto "Desenvolvimento de uma base de dados da bacia hidrográfica do Rio Negro-RS", aprovado no edital do Programa de Iniciação em Ciências, Matemática, Engenharia, Tecnologias Criativas e Letras (PICMEL) da Fundação de Amparo à Pesquisa do Rio Grande do Sul (Fapergs). O objetivo principal das ações de extensão foi capacitar os bolsistas do projeto (seis estudantes e dois professores de uma escola de ensino médio) para trabalhar com geoprocessamento nas áreas de recursos hídricos e gestão territorial. O método utilizado para o desenvolvimento do projeto constituiu-se de: a) definição de ações de extensão; b) planejamento das ações; c) realização das ações planejadas; e d) avaliação das ações realizadas. A partir da realização das ações programadas os estudantes foram capazes de elaborar as atividades propostas, auxiliando no desenvolvimento da base de dados da bacia hidrográfica.

Palavras-chave: Educação. Meio ambiente. Extensão universitária.

\begin{abstract}
This paper presents the university extension actions developed at the Dr. Karlos Kluwe State High School, in Bagé, State of Rio Grande do Sul, within the scope of the project "Development of a database of the Negro River bay, Rio Grande do Sul, Brazil", approved in the Program for Initiation in Sciences, Math, Engineering, Creative Technologies and Letters (PICMEL) of the Research Support Foundation from Rio Grande do Sul (Fapergs). The main objective of the extension actions was to train the project's scholarship owners (six students and two teachers from a high school) to work with geoprocessing applied to water resources and territorial management. The method used for the development of the project consisted of: a) definition of extension actions; b) action planning; c) carrying out the planned actions; and d) evaluation of the actions taken. From the completion of the programmed actions, the students were able to elaborate the proposed activities, assisting in the development of the bay area database.
\end{abstract}

Keywords: Education. Environment. University extension.

\footnotetext{
${ }^{1}$ Doutor em Engenharia Civil pela Universidade Federal de Santa Catarina, Brasil, professor da Universidade Federal do Pampa, Bagé, Rio Grande do Sul, Brasil (alexandro.schafer@unipampa.edu.br).
} 


\section{INTRODUÇÃO}

No ano de 2014, a Fundação de Amparo à Pesquisa do Rio Grande do Sul lançou o edital $n^{\circ}$ 03/2014: Programa de Iniciação em Ciências, Matemática, Engenharias, tecnologias criativas e Letras (PICMEL) (FAPERGS, 2014). O objetivo do programa era despertar a vocação científica e incentivar talentos potenciais nessas áreas do conhecimento, em alunos do ensino público, fundamental ou médio do Rio Grande do Sul. O edital previa a concessão de seis bolsas de iniciação científica júnior e duas bolsas de supervisão para professores de ensino médio.

$\mathrm{Na}$ Universidade Federal do Pampa (Unipampa), desde o ano de 2012, está em desenvolvimento o projeto de extensão universitária "Bacia hidrográfica do Rio Negro-RS: conhecer para gerenciar", que tem como objetivo principal promover ações que resultem em conhecimento acerca dos aspectos físicos, sociais e ambientais sobre essa bacia hidrográfica.

A bacia hidrográfica do rio Negro-RS pertence à região hidrográfica do Uruguai e contempla uma área de aproximadamente $3.000 \mathrm{~km}^{2}$, abrangendo parcialmente os municípios gaúchos de Aceguá, Bagé, Candiota, Hulha Negra e Dom Pedrito, incluindo-se as áreas urbanas de Bagé e Hulha Negra. De acordo com Departamento de Água e Esgoto de Bagé (DAEB, 2007), os principais problemas encontrados na bacia do Rio Negro em território brasileiro estão relacionados: ao déficit hídrico; aos efluentes industriais e domésticos das áreas urbanas; aos depósitos de resíduos; à extração de materiais nas margens dos cursos d'água e à ocupação de áreas de preservação permanentes por atividades rurais. Segundo a Agência Nacional de Águas (ANA, 2015), o Rio Negro está incluído entre os 16\% dos rios federais com trechos críticos segundo o balanço hídrico qualiquantitativo, apresentando criticidade tanto qualitativa como quantitativa.

Embora o projeto de extensão universitária viesse obtendo relativo êxito, a interação com os jovens de escolas públicas, que estava previsto desde o início do projeto nunca havia, de fato, ocorrido. Como argumentam Albrecht e Bastos (2020), desconstruir muros, aproximar a Universidade da sociedade e possibilitar que a sociedade se empodere da Universidade é substancial para que a extensão se fortaleça cada vez mais e torne a Universidade de fato universal. Cabe ressaltar, ainda, que a extensão universitária é definida, conforme o Plano Nacional de Extensão, como o processo educativo, cultural e científico que articula o ensino e 
a pesquisa de forma indissociável e viabiliza a relação transformadora entre a Universidade e a sociedade (FORPROEX, 2007).

Nesse sentido, a partir do lançamento do edital Fapergs/PICMEL vislumbrou-se a oportunidade de atender a duas demandas relacionadas ao projeto: a) a capacitação de alunos do ensino médio com relação à Política Nacional de Recursos Hídricos (PNRH) instituída em 1997 e também com relação aos aspectos físicos e ambientais da bacia hidrográfica do Rio Negro-RS; b) o desenvolvimento de produtos cartográficos da área de abrangência da bacia hidrográfica.

Com base nessa percepção, submeteu-se ao edital Fapergs/PICMEL, a proposta de projeto de pesquisa intitulada "Desenvolvimento de uma base de dados da bacia hidrográfica do Rio Negro-RS”. A partir da aprovação do projeto nessa agência de fomento, deu-se início a uma série de ações de extensão universitária que tinham como objetivo principal capacitar estudantes e professores bolsistas quanto à PNRH e à aplicação de técnicas de geoprocessamento nas áreas de recursos hídricos e gestão territorial. Este texto apresenta as principais ações de extensão planejadas e realizadas ao longo do período de execução do projeto, bem como os resultados alcançados.

\section{MATERIAL E MÉTODOS}

As ações de extensão foram definidas do contexto do projeto de pesquisa "Desenvolvimento de uma base de dados da bacia hidrográfica do Rio Negro-RS" e do projeto de extensão "Bacia hidrográfica do Rio Negro-RS: conhecer para gerenciar".

A primeira etapa do projeto foi a definição das ações de extensão universitária necessárias para que os estudantes e professores da escola pública obtivessem conhecimentos básico acerca da PNRH e fossem capazes de desenvolver atividades utilizando técnicas de geoprocessamento. Para a definição dessas ações, havia as seguintes questões envolvidas: a) os estudantes e professores da escola pública não possuíam conhecimento acerca da PNRH e de Geoprocessamento; b) as ações deveriam ser executadas, ao menos parcialmente, nas dependências da Escola Estadual de Ensino Médio Doutor Carlos Kluwe que possuía limitações quanto ao espaço físico para o desenvolvimento das atividades e também quanto ao acesso à internet; c) as ações envolveriam os bolsistas de ensino, extensão ou pesquisa de 
cursos de graduação em Engenharia da Unipampa, que não tinham experiência no desenvolvimento de atividades com estudantes de ensino médio.

As ações de extensão universitária foram definidas com base em uma análise das necessidades de capacitação dos bolsistas versus as possibilidades quanto à infraestrutura e ao pessoal disponíveis na época.

Após a definição das ações de extensão, a próxima etapa foi o seu planejamento. Inicialmente, o planejamento das ações se deu de maneira empírica, sem uma metodologia definida. Os professores identificavam ações e transmitiam as tarefas verbalmente para os bolsistas da universidade. Com o passar do tempo e com a experiência adquirida, optou-se por documentar, sistematizar e discutir as ações entre a equipe do projeto, definindo metas, prazos e resultados esperados (além dos recursos disponíveis), e só então partir para a execução da ação.

A etapa de execução consistiu em colocar em prática as ações planejadas na fase anterior, realizando ajustes e/ou adaptações com relação ao planejamento prévio quando necessário. Os locais de execução das ações foram: a) a Unipampa (Laboratório de Modelagem, Simulação Computacional e Geoprocessamento (LMSC-Geo)), no auditório ou em salas de aula); e b) a Escola Dr. Carlos Kluwe. As atividades de campo foram realizadas na área de abrangência da bacia hidrográfica, nas áreas urbana e rural.

A última etapa do projeto consistiu na avaliação de cada ação executada. A avaliação foi realizada de diferentes maneiras, de acordo com o tipo de ação. As palestras e cursos de extensão foram avaliados por meio de questionários em que os ouvintes avaliavam o conteúdo da ação apresentada. O nível de aprendizado dos participantes foi verificado a partir da aplicação de questionários sobre os assuntos abordados.

A avaliação serviu para alocar os professores e bolsistas em dois grupos distintos: Grupo 1, cujos membros desenvolveriam atividades relacionadas ao Sistema de Informações Geográficas; Grupo 2, cujos membros desenvolveriam atividades relacionadas ao mapeamento do uso e cobertura da terra na bacia hidrográfica do rio Negro. Cada grupo foi formado por um professor orientador e por três alunos bolsistas.

Outras ações desenvolvidas ao longo do período de execução do projeto, como os seminários em que os bolsistas de ensino médio realizaram exposições sobre o projeto e sobre as 
atividades que estavam desenvolvendo, foram avaliadas de maneira subjetiva pela equipe do projeto do edital Fapergs/PICMEL.

\section{RESULTADOS E DISCUSSÃO}

As ações de extensão universitária, realizadas ao longo do período de desenvolvimento do projeto foram: cursos teórico/práticos; seminários; palestras; desenvolvimento de material educacional; desenvolvimento de material cartográfico.

Inicialmente, foram elaborados e ministrados cinco cursos teórico/práticos sobre a PNRH, sobre geoprocessamento e sobre desenho auxiliado por computador. Os cursos são apresentados no Quadro 1.

Quadro 1 - Cursos de extensão universitária realizados

\begin{tabular}{|c|c|c|}
\hline Curso & Público alvo & Objetivo \\
\hline $\begin{array}{c}\text { Introdução à Política } \\
\text { Nacional de Recursos } \\
\text { Hídricos }\end{array}$ & $\begin{array}{l}\text { Estudantes universitários, } \\
\text { estudantes de ensino médio, } \\
\text { profissionais de órgãos } \\
\text { públicos e prefeituras. }\end{array}$ & $\begin{array}{c}\text { Proporcionar conhecimento } \\
\text { sobre a Lei } n^{\circ} 9.433, \text { de } 8 \text { de } \\
\text { janeiro de } 1997 \text { (BRASIL, } \\
\text { 1997). }\end{array}$ \\
\hline $\begin{array}{c}\text { Introdução ao Desenho } \\
\text { Auxiliar por Computador } \\
\text { (Computer Aided Design - } \\
\text { CAD) aplicado ao } \\
\text { Geoprocessamento }\end{array}$ & $\begin{array}{l}\text { Estudantes universitários, } \\
\text { estudantes de ensino médio. }\end{array}$ & $\begin{array}{l}\text { Capacitar os participantes a } \\
\text { realizar desenhos utilizando } \\
\text { softwares CAD. }\end{array}$ \\
\hline $\begin{array}{c}\text { Introdução ao Sensoriamento } \\
\text { Remoto e ao Processamento } \\
\text { Digital de Imagens }\end{array}$ & $\begin{array}{l}\text { Estudantes universitários, } \\
\text { estudantes de ensino médio. }\end{array}$ & $\begin{array}{l}\text { Capacitar os participantes no } \\
\text { processamento digital de } \\
\text { imagens de sensoriamento } \\
\text { remoto para estudos de uso e } \\
\text { cobertura da terra. }\end{array}$ \\
\hline $\begin{array}{l}\text { Introdução aos Sistemas de } \\
\text { Informações Geográficas }\end{array}$ & $\begin{array}{l}\text { Estudantes universitários, } \\
\text { estudantes de ensino médio, } \\
\text { profissionais de prefeituras e } \\
\text { órgãos públicos. }\end{array}$ & $\begin{array}{c}\text { Capacitar os participantes a } \\
\text { utilizar softwares de Sistema de } \\
\text { Informações Geográficas SIG } \\
\text { gratuitos para visualizar e } \\
\text { manipular dados espaciais, bem } \\
\text { como realizar consultas simples } \\
\text { a esses dados. }\end{array}$ \\
\hline Introdução ao Sistema de & Estudantes universitários, & Capacitar os participantes a \\
\hline
\end{tabular}




\begin{tabular}{|c|c|c|}
\hline Informações Geográficas & estudantes de ensino médio. & utilizar as funcionalidades do \\
Web (SIGWeb) da Bacia & & SIGWeb da bacia hidrográfica e \\
Hidrográfica do Rio Negro- & & a atuarem como administradores \\
RS & & do sistema. \\
\hline
\end{tabular}

Fonte: O autor (2020).

Os cursos tiveram carga horária entre 12 e 20 horas e foram ministrados na Unipampa e na Escola Dr. Carlos Kluwe. Paralelamente aos cursos, foram realizadas saídas a campo, na área de abrangência da bacia hidrográfica do rio Negro-RS, com o objetivo de proporcionar uma visão abrangente sobre ela, no contexto da PNRH e do geoprocessamento. Todos os alunos bolsistas e os professores da Escola Dr. Carlos Kluwe, os bolsistas do Programa de Bolsas de Desenvolvimento Acadêmico (PBDA) da Unipampa e o coordenador do projeto participaram das saídas a campo.

Após a realização dos cursos e respectivas avaliações, dividiu-se a equipe do projeto em dois grupos, conforme citado na seção anterior. No Quadro 2, apresenta-se uma síntese das atividades executadas pelos integrantes do Grupo 1. No quadro 3, apresenta-se uma síntese das atividades executadas pelos integrantes do Grupo 2.

Quadro 2 - atividades realizadas pelo Grupo 1

\begin{tabular}{|l|l|}
\hline \multicolumn{1}{|c|}{ Atividade } & \multicolumn{1}{|c|}{ Descrição } \\
\hline $\begin{array}{l}\text { Pesquisa por material } \\
\text { bibliográfico e cartográfico } \\
\text { da abrangência da bacia } \\
\text { hidrográfica. }\end{array}$ & $\begin{array}{l}\text { A pesquisa por material bibliográfico e cartográfico foi realizada } \\
\text { com o objetivo de verificar quais são os estudos desenvolvidos no } \\
\text { âmbito da bacia hidrográfica, bem como os mapas e dados } \\
\text { espaciais que já foram gerados e que podem fazer parte da base de } \\
\text { dados a ser construída. Foram realizadas buscas em âmbito } \\
\text { municipal: prefeituras municipais de Aceguá, Bagé, Candiota, } \\
\text { Dom Pedrito e Hulha Negra, no Departamento de Água e Esgoto } \\
\text { de Bagé (DAEB), na Universidade da Região da Campanha } \\
\text { (URCAMP) e na Associação dos Produtores Rurais; em âmbito } \\
\text { estadual: Fundação Estadual de Proteção Ambiental (FEPAM), } \\
\text { Departamento de Recursos Hídricos da Secretaria Estadual de } \\
\text { Recursos Hídricos (DRH/SEMA); e em âmbito nacional: Instituto } \\
\text { Brasileiro de Geografia e Estatística (IBGE), INCRA, Ministério } \\
\text { do Meio Ambiente (MMA), INMET, Agência Nacional de Águas } \\
\text { (ANA), entre outros. }\end{array}$ \\
\hline $\begin{array}{l}\text { Preparação e edição dos } \\
\text { dados preexistentes. }\end{array}$ & $\begin{array}{l}\text { Como os dados preexistentes foram obtidos de fontes diversas, e } \\
\text { produzidos para diferentes finalidades, foi necessário prepará-los e }\end{array}$ \\
\hline
\end{tabular}




\begin{tabular}{|l|l|}
\hline & $\begin{array}{l}\text { editá-los para posterior inserção na base de dados. A preparação } \\
\text { dos dados compreendeu a escanerização e a vetorização de } \\
\text { produtos cartográficos ou dados espaciais, além da reprojeção dos } \\
\text { arquivos, quando necessário. A edição dos dados compreendeu } \\
\text { alterações ou ajustes em suas geometrias e/ou atributos, visando } \\
\text { obter os dados necessários e no formato adequado para a realização } \\
\text { das modelagens hidrológica e de qualidade da água. Os programas } \\
\text { utilizados para editar os dados foram o Spring, o Terraview, o } \\
\text { gvSIG, o ArcGIS, o ENVI e o Draft Sight. }\end{array}$ \\
\hline $\begin{array}{l}\text { Desenvolvimento } \\
\text { Sistema de Informações } \\
\text { Geográficas (SIG). }\end{array}$ & $\begin{array}{l}\text { Os dados existentes, editados ou não, foram organizados com o } \\
\text { auxílio dos softwares de SIG, que foram utilizados para arquivar, } \\
\text { manipular, visualizar e consultar as informações na base de dados. }\end{array}$ \\
\hline $\begin{array}{l}\text { Organização e edição dos } \\
\text { dados provenientes do } \\
\text { monitoramento } \\
\text { qualiquantitativo na bacia } \\
\text { hidrográfica. }\end{array}$ & $\begin{array}{l}\text { Os dados provenientes da realização dos monitoramentos } \\
\text { referentes à qualidade e quantidade da água vêm sendo obtidos } \\
\text { desde o mês de março de 2014. À medida que esses dados foram } \\
\text { obtidos, foi necessário inseri-los na base de dados, periodicamente. } \\
\text { A tarefa de inserir os dados compreendeu: a) a organização dos } \\
\text { dados medidos em campo; b) a digitação dos dados em planilhas } \\
\text { eletrônicas; c) o registro de novas instâncias dos atributos; e d) a } \\
\text { inserção/alteração de geometrias. }\end{array}$ \\
\hline $\begin{array}{l}\text { Atualização do Sistema de } \\
\text { Informações Geográficas }\end{array}$ & $\begin{array}{l}\text { Como foram gerados novos dados sobre a bacia hidrográfica } \\
\text { periodicamente, foi necessário proceder à atualização periódica da } \\
\text { estrutura do SIG. A atualização compreendeu a inserção dos dados } \\
\text { de monitoramento no SIG e os ajustes e alterações em sua } \\
\text { estrutura, a medida que o número de entidades presentes na base de } \\
\text { dados foi aumentando. }\end{array}$ \\
\hline
\end{tabular}

Fonte: O autor (2020).

Quadro 3 - Atividades realizadas pelo grupo 2 do projeto de pesquisa

\begin{tabular}{|c|c|}
\hline Atividade & Descrição \\
\hline $\begin{array}{lccc}\text { Pesquisa por } & \text { imagens } & \text { de } \\
\text { satélite da } & \text { área } & \text { de } \\
\text { abrangência } & \text { da } & \text { bacia } \\
\text { hidrográfica } & & \end{array}$ & $\begin{array}{l}\text { As imagens de satélite utilizadas para a confecção dos mapas de } \\
\text { uso e ocupação do solo foram provenientes da série de satélites } \\
\text { Landsat. A pesquisa por imagens de satélite foi realizada no } \\
\text { arquivo de imagens do grupo de pesquisa em modelagem e } \\
\text { simulação computacional da Unipampa e no arquivo de imagens } \\
\text { do United States Geological Survey (USGS), em que as imagens } \\
\text { são disponibilizadas gratuitamente. }\end{array}$ \\
\hline $\begin{array}{l}\text { Obtenção das imagens de } \\
\text { satélite }\end{array}$ & $\begin{array}{l}\text { Com base nas imagens disponíveis, foram definidas as imagens a } \\
\text { serem utilizadas no estudo proposto. Foram utilizadas imagens }\end{array}$ \\
\hline
\end{tabular}




\begin{tabular}{|c|c|}
\hline & $\begin{array}{l}\text { desde o ano de } 1977 \text {. No caso das imagens dos arquivos do } \\
\text { USGS, se procedeu o download das imagens. }\end{array}$ \\
\hline $\begin{array}{l}\text { Registro } \\
\text { georreferenciamento das } \\
\text { imagens }\end{array}$ & $\begin{array}{l}\text { As imagens foram registradas e georreferenciadas com base em } \\
20 \text { pontos de controle obtidos para a bacia hidrográfica, utilizando } \\
\text { receptores GNSS L1/L2 existentes na Unipampa. }\end{array}$ \\
\hline $\begin{array}{l}\text { Recorte e confecção de } \\
\text { mosaicos das imagens de } \\
\text { satélite na área de } \\
\text { abrangência da bacia } \\
\text { hidrográfica }\end{array}$ & $\begin{array}{l}\text { As cenas foram recortadas de acordo com o arquivo vetorial da } \\
\text { bacia hidrográfica do rio Negro-RS, disponibilizado no site da } \\
\text { Secretaria Estadual de Meio Ambiente do Rio Grande do Sul } \\
\text { (SEMA). Como a área de abrangência da bacia hidrográfica do rio } \\
\text { Negro encontra-se entre os fusos } 21 \text { e } 22 \text {, muitas cenas das } \\
\text { imagens de satélite existentes não cobrem toda a área da bacia. } \\
\text { Nesses casos, após o recorte das duas cenas adjacentes, foram } \\
\text { confeccionados os mosaicos da bacia hidrográfica. }\end{array}$ \\
\hline $\begin{array}{lcc}\text { Aplicação de técnicas de } \\
\text { Processamento Digital de } \\
\text { Imagem (PDI) }\end{array}$ & $\begin{array}{l}\text { Foram aplicadas técnicas de PDI comumente utilizadas em } \\
\text { imagens de satélite. Nessa etapa, foram geradas composições } \\
\text { coloridas de diferentes datas para auxiliar no processo de } \\
\text { classificação supervisionada. }\end{array}$ \\
\hline $\begin{array}{l}\text { Aplicação de técnicas de } \\
\text { classificação supervisionada }\end{array}$ & $\begin{array}{l}\text { A classificação supervisionada seguiu as seguintes etapas: } \\
\text { definição das classes de mapeamento, escolha das amostras de } \\
\text { classificação, aplicação do algoritmo de classificação. }\end{array}$ \\
\hline $\begin{array}{l}\text { Aplicação de técnicas de } \\
\text { pós-classificação }\end{array}$ & $\begin{array}{l}\text { A etapa seguinte à classificação das imagens foi a etapa de pós- } \\
\text { classificação que buscou melhorar os resultados da classificação } \\
\text { supervisionada, eliminando ou amenizando os erros provenientes } \\
\text { da utilização do algoritmo para a classificação utilizado (Máxima } \\
\text { Verossimilhança). }\end{array}$ \\
\hline $\begin{array}{l}\text { Confecção de mapas de uso e } \\
\text { ocupação do solo da bacia } \\
\text { hidrográfica }\end{array}$ & $\begin{array}{l}\text { A última etapa de trabalho do grupo } 2 \text { consistiu na confecção de } \\
\text { mapas de uso e ocupação do solo da bacia hidrográfica dos } \\
\text { períodos analisados durante o projeto. Foram produzidos sete } \\
\text { mapas de uso e ocupação do solo, dos anos de } 1977,1985,1996 \text {, } \\
2001,2003,2013 \text { e } 2014 \text {. }\end{array}$ \\
\hline
\end{tabular}

Fonte: O autor (2020).

Ao longo do período de execução do projeto, foram realizadas reuniões periódicas, tanto com os professores orientadores quanto com os bolsistas, a fim de verificar e avaliar o andamento das atividades propostas, bem como orientar os professores e dirimir dúvidas. As reuniões ocorreram na Escola Estadual Dr. Carlos Kluwe (oito reuniões) e na Unipampa (doze reuniões). Nas reuniões que envolveram todo o grupo de alunos e professores, contou-se com o transporte (micro-ônibus) da Unipampa. 
Os bolsistas de pesquisa ( 2 alunos), de extensão (3 alunos) e de ensino ( 2 alunos) da Unipampa que estavam sob a orientação do coordenador do projeto auxiliaram os bolsistas da Escola Dr. Carlos Kluwe a desenvolver todas as atividades propostas no escopo do projeto de pesquisa.

No dia 25 de maio de 2015, foi realizado um seminário na escola, no qual os alunos bolsistas do projeto apresentaram para os demais alunos da escola o seu trabalho e os primeiros resultados alcançados. Na ocasião, aproximadamente cem alunos participam do seminário.

Em outubro de 2015 (último mês do projeto Fapergs/PICMEL) foi realizado, na Unipampa, o seminário de encerramento do projeto de pesquisa do edital Fapergs/PICMEL, paralelamente ao seminário trimestral do Laboratório de Modelagem, Simulação Computacional e Geoprocessamento (LMSC-Geo) da Unipampa. O Seminário contou com todos os alunos bolsistas e voluntários da Escola Dr. Carlos Kluwe, além dos professores da escola e dos bolsistas do Laboratório de Modelagem, Simulação Computacional e Geoprocessamento (LMSC-Geo). Na ocasião, tanto os bolsistas do projeto Fapergs/PICMEL quanto os bolsistas do LMSC-Geo apresentaram os trabalhos desenvolvidos ao longo de 2015. Foi realizado um balanço das atividades desenvolvidas ao longo do projeto do edital PICMEL, em que alunos e professores expuseram as principais dificuldades e desafios encontrados ao longo do projeto, bem como a experiência adquirida.

Dentre os resultados obtidos a partir da realização do projeto, destaca-se o mapeamento das alterações no uso e cobertura da terra na bacia hidrográfica do Rio Negro-RS entre 1977 e 2014. Esse mapeamento foi realizado utilizando imagens da série de satélites Landsat. A tabela 1 traz informações sobre as cenas utilizadas no estudo.

As imagens foram processadas utilizando técnicas de Processamento Digital de Imagens (PDI) e classificadas utilizando o método da Máxima Verossimilhança (MaxVer) no programa computacional ENVI. Por fim, trabalhou-se na pós-classificação dos mapas de uso e cobertura da terra gerados na classificação supervisionada.

Os resultados indicam que houve uma significativa alteração nos padrões de paisagem na bacia hidrográfica do Rio Negro-RS, no período analisado. 
Tabela 1 - Quantificação do uso e cobertura da terra na bacia hidrográfica do rio Negro-RS entre 1977 e 2014

\begin{tabular}{|c|c|c|c|c|c|c|c|c|c|c|}
\hline \multirow{3}{*}{ Classe } & \multicolumn{10}{|c|}{ Ano da cena analisada } \\
\hline & \multicolumn{2}{|c|}{1977} & \multicolumn{2}{|c|}{1985} & \multicolumn{2}{|c|}{1996} & \multicolumn{2}{|c|}{2003} & \multicolumn{2}{|c|}{2014} \\
\hline & $\mathrm{Km}^{2}$ & $\%$ & $\mathbf{K m}^{2}$ & $\%$ & $\mathbf{K m}^{2}$ & $\%$ & $\mathrm{Km}^{2}$ & $\%$ & $\mathrm{Km}^{2}$ & $\%$ \\
\hline Urbano & 14,96 & 0,45 & 21,26 & 0,71 & 21,04 & 0,71 & 24,98 & 0,83 & 28,13 & 0,92 \\
\hline Florestal & 714,42 & 23,83 & 366,30 & 12,20 & 413,01 & 13,78 & 254,60 & 8,49 & 144,95 & 4,85 \\
\hline Campestre & 1975,30 & 65,89 & 2094,80 & 69,88 & 1989,30 & 66,35 & 2017,22 & 67,28 & 1283,80 & 42,00 \\
\hline Água & 33,25 & 1,11 & 68,16 & 2,27 & 59,90 & 1,20 & 71,88 & 2,40 & 91,38 & 3,04 \\
\hline $\begin{array}{l}\text { Cultura } \\
\text { temporária }\end{array}$ & 260,70 & 8,69 & 417,01 & 13,91 & 486,12 & 16,12 & 471,36 & 15,72 & 1603,20 & 46,92 \\
\hline Silvicultura & - & - & 31,25 & 1,04 & 29,70 & 0,99 & 158,87 & 5,30 & 47,09 & 1,56 \\
\hline
\end{tabular}

Fonte: O autor (2020).

A Figura 1 apresenta o mapa de uso e cobertura da terra da bacia hidrográfica do Rio Negro em dezembro de 2014, elaborado com o auxílio dos alunos bolsistas de iniciação científica júnior do Grupo 1, com base em IBGE (2013). 
Figura 1 - Mapa de uso e cobertura da terra na bacia hidrográfica do Rio Negro-RS em 2014

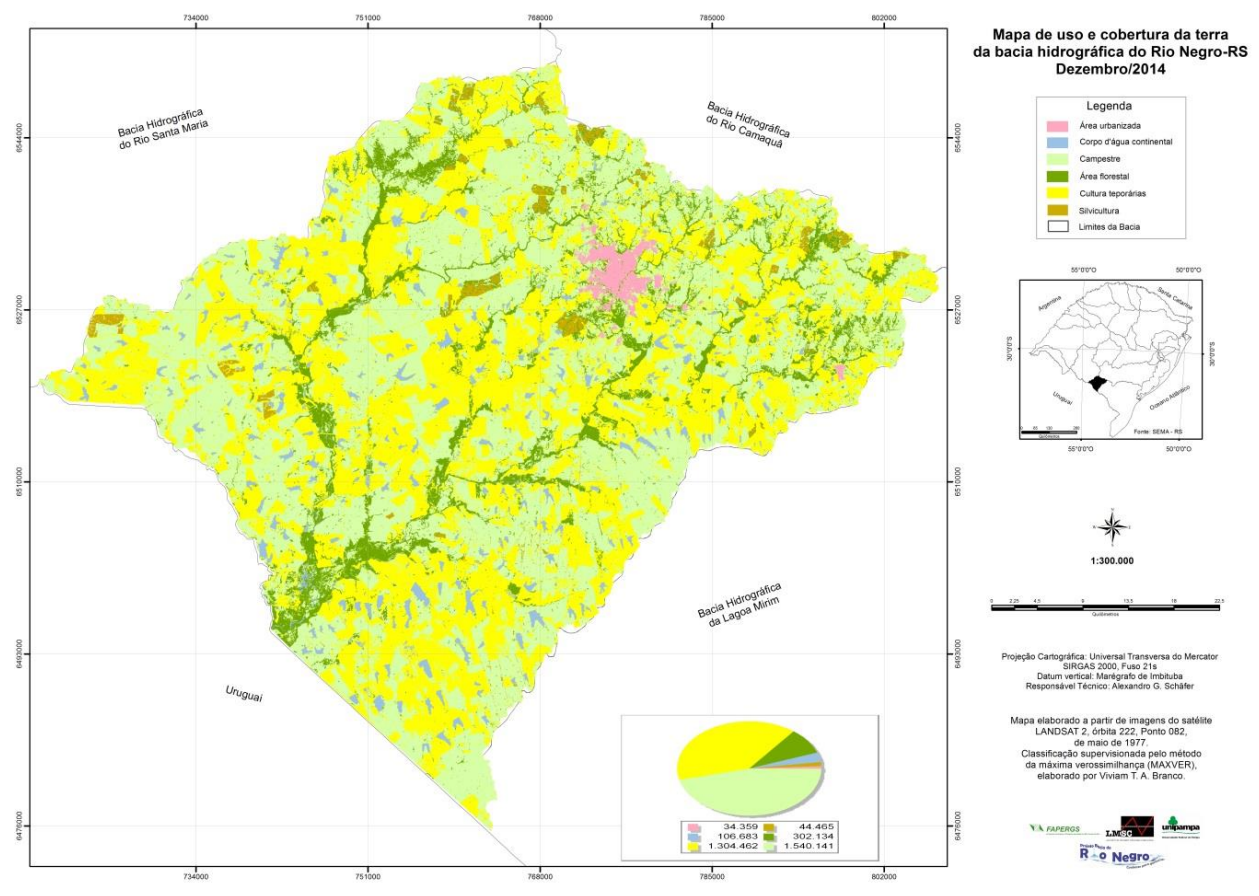

Fonte: O autor (2020).

Como é possível verificar na Tabela 1 e na Figura 1, as áreas ocupadas por campos (classe “campestre") e por mata nativa (classe "áreas florestais") tiveram uma considerável redução, enquanto as áreas ocupadas por atividades agrícolas (classe "cultura temporária") aumentaram de 260,70 km², em 1977, para 1603,20 km² em 2014.

\section{CONSIDERAÇÕES FINAIS}

A partir da realização das ações de extensão universitária, foi possível capacitar os bolsistas de iniciação científica júnior e os professores da Escola Dr. Carlos Kluwe quanto à PNRH e quanto à utilização de técnicas de geoprocessamento para produção de material cartográfico, alcançando o objetivo principal das ações.

Foi possível criar os mapas de uso e ocupação do solo desde a década de 1970 até os dias atuais, proporcionando uma visão geral acerca da dinâmica das alterações do uso e ocupação do solo que ocorreu na bacia hidrográfica ao longo dos últimos 37 anos. Uma quantidade considerável de informação cartográfica, tanto da área rural quanto da área urbana, foi editada e inserida no SIG da bacia. Foi realizada uma pesquisa sobre as medições de parâmetros de qualidade da água realizadas até hoje nos cursos d'água da bacia hidrográfica. Posteriormente, 
foram criados arquivos shapefile dos pontos de medição, contendo como atributos todos os parâmetros medidos. Também foram desenvolvidos estudos sobre o modelo digital do terreno da bacia hidrográfica, que é fundamental para os estudos de modelagem hidrológica.

Os professores da escola participaram das reuniões do Comitê de Gerenciamento da Bacia Hidrográfica do rio Negro $(\mathrm{CBRN})$ que ocorreram mensalmente entre os meses de março e dezembro de 2015, na Associação Rural de Bagé. Isso contribuiu para o aumento do entendimento dos professores sobre PNRH e sobre alguns dos problemas e demandas existentes na bacia hidrográfica.

O início do projeto foi marcado por dificuldades com relação à logística e ao acompanhamento das atividades realizadas pelos alunos bolsistas. Com o passar do tempo, foi possível adaptar a infraestrutura existente e superar as dificuldades encontradas inicialmente.

O projeto previa a participação dos alunos bolsistas da Escola Dr. Carlos Kluwe em eventos de iniciação científica. No entanto, não houve eventos desse tipo durante o período de vigência do projeto (novembro de 2014 a outubro de 2015) na cidade de Bagé e nos municípios próximos. Como os alunos de ensino médio tinham certas restrições financeiras, não foi possível que eles viajassem para participar de eventos de iniciação científica em outros municípios da região.

O contato com os alunos de ensino médio foi de grande valia tanto para os professores quanto para os alunos de graduação da Unipampa que participam do Grupo de Pesquisa em modelagem e Simulação Computacional. Os professores tiveram a oportunidade de ter contato com alunos de uma faixa etária com os quais não estão acostumados a trabalhar na universidade, o que possibilitou uma visão mais abrangente do campo educacional. Além disso, verificou-se que os alunos têm potencial para trabalhar em projetos de pesquisa nas áreas de engenharia. Dois dos alunos participantes do projeto PICMEL agora são bolsistas do programa de bolsas de ensino médio no CNPQ e estão trabalhando na continuação do projeto de pesquisa submetido ao edital PICMEL.

Embora o ganho para os professores da Unipampa tenha sido considerável, acreditamos que o ganho obtido pelos alunos de graduação da Unipampa, participantes do projeto, tenha sido maior. Os alunos auxiliaram a ministrar os cursos de extensão universitária e foram responsáveis pelo acompanhamento das atividades dos alunos bolsistas do projeto PICMEL. Com isso, tiveram a oportunidade de repassar conhecimentos obtidos durante a graduação e 
durante os trabalhos de pesquisa no LMSC-Geo aos alunos bolsistas. Além disso, tiveram a oportunidade de vivenciar uma realidade diferente da que eles vivem, superando as dificuldades e os desafios que existiram ao longo do desenvolvimento do projeto. E, talvez o mais importante, tiveram a oportunidade de trabalhar em equipe, com pessoas de diferentes níveis de escolaridade e realidades.

\section{REFERÊNCIAS}

AGÊNCIA NACIONAL DE ÁGUAS. Conjuntura dos recursos hídricos no Brasil: Informe 2014. Brasília, 2015. Disponível em: http://www.snirh.gov.br/portal/snirh/centraisde-conteudos/conjuntura-dos-recursos-hidricos. Acesso em: 15 maio 2020.

ALBRECHT, E.; BASTOS, A. S. A. M. Extensão e sociedade: diálogos necessários. Em Extensão, Uberlândia, v. 19, n. 1, 2020. Disponível em: http://www.seer.ufu.br/index.php/revextensao/article/view/53428. Acesso em: 14 maio 2020. Doi: 10.14393/REE-v19n12020-53428.

BRASIL. Ministério do Meio Ambiente dos Recursos Hídricos e da Amazônia Legal. Política Nacional de Recursos Hídricos. Lei $n^{\circ}$ 9.433, de 8 de janeiro de 1997. Institui a Política Nacional de Recursos Hídricos, cria o Sistema Nacional de Gerenciamento de Recursos Hídricos, regulamenta o inciso XIX do art. 21 da Constituição Federal, e altera o art. $1^{\circ}$ da Lei $\mathrm{n}^{\circ}$ 8.001, de 13 de março de 1990, que modificou a Lei no 7.990, de 28 de dezembro de 1989. Brasília, DF, Diário Oficial da União, 9 jan. 1997.

DEPARTAMENTO DE ÁGUA E ESGOTO DE BAGÉ. Caracterização e diagnóstico da bacia do Rio Negro em Território Brasileiro-RS. Contrato nº 004/2007. Bagé, 2007.

INSTITUTO BRASILEIRO DE GEOGRAFIA E ESTATÍSTICA - IBGE. Departamento de Recursos Naturais e Estudos Ambientais. Manual técnico de uso da terra. Rio de Janeiro: IBGE, 2013.

FÓRUM DE PRÓ-REITORES DE EXTENSÃO DAS UNIVERSIDADES PÚBLICAS BRASILEIRAS. Extensão universitária: organização e sistematização. Belo Horizonte: Coopmed, 2007.

FUNDAÇÃO DE AMPARO A PESQUISA DO RIO GRANDE DO SUL. Edital n 03/2014: Programa de Iniciação em Ciências, Matemática, Engenharias, Tecnologias Criativas e Letras (PICMEL). 2014. Disponível em: https://fapergs.rs.gov.br/edital-03-2014-programa-deiniciacao-em-ciencias-matematica-engenharias-tecnologias-criativas-e-letras-picmel. Acesso em: 10 mar. 2020.

Submetido em 9 de junho de 2020.

Aprovado em 20 de julho de 2020. 